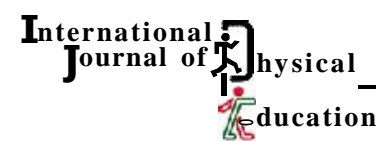

Volume 8 | Issue 1 | April, 2015 | 67-68

\title{
A study of relationship between selected anthropometric variables and shooting ability in handball
}

\author{
GYAN PRAKASH ARJERIA
}

Received : 23.08.2014; Accepted : 27.03.2015

Author for correspondence

GYAN PRAKASH ARJERIA

Major Dhyanchand Institute of

Physical Education, Bundelkhand

University, JHANSI (U.P.) INDIA

Email: gyan.arjeria@gmail.com
DOI : $10.15740 / \mathrm{HAS} / \mathrm{IJPE} / 8.1 / 67-68$

e ISSN-0976-7924 Visit us : www.researchjournal.co.in
Research Note

\section{-ABSTRACT}

The purpose of the study was to find out the relationship between selected anthropometric variable (standing height) and shooting ability in handball. To achieve these objective twenty male handball players of interuniversity level from Devi Ahilya University were randomly selected as subjects. It was hypothesized that there will be a significant relationship between standing height and shooting ability in handball. Scores obtained from Zinne's Team handball Test Battery were used as criterion measure. Analysis of the scores was done using Pearson's product moment correlation at 0.05 level of significance which showed that the obtained value of $\mathrm{r}$ was $=-0.43521$ while the required value of $r$ at 0.05 level of confidence with 18 degree of freedom is $=0.444$ which is not significant it clearly indicates a very low (-ve) relationship.

- KEY WORDS : Anthropometry, Zinne's team handball test battery

- HOW TO CITE THIS PAPER : Arjeria, Gyan Prakash (2015). A study of relationship between selected anthropometric variables and shooting ability in handball. Internat. J. Phy. Edu., 8 (1) : 67-68. 